\title{
The Expression and Significance of Nerve Growth Factor Receptor in Ovarian Cancer
}

\author{
Lihong Bao \\ Medical College, Inner Mongolia University for the Nationalities, Tongliao, Inner Mongolia, 028000, \\ China \\ baolihong71@163.com
}

Keywords: Nerve Growth Factor, Ovarian Cancer

\begin{abstract}
NGF and its receptor are expressed in multiple nervous system and tumor of the non-nervous system, which also participate in tumor proliferation, differentiation, apoptosis, angiogenesis and other biological behaviors. In this paper, it takes the interpretation of nerve growth factor (NGF) as the breakthrough point, analyzing the expression of TrkA protein in benign, borderline and malignant epithelial ovarian tumor, exploring the significance of expression of the nerve growth factor receptor, so as to provide the theoretical basis for the diagnosis and treatment of ovarian tumor.
\end{abstract}

\section{Introduction}

Ovarian cancer is a common gynecological tumor, the mortality rate of ovarian cancer ranks the first place in gynecological malignancies. The differentiation degree and prognosis of tumors have absolute relationship. Therefore, prediction and diagnosis of ovarian tumor malignant degree of patients with treatment and prognosis can have very important significance. Tyrosine protein kinase A (TrkA) as the high affinity receptor of nerve growth factor (NGF), after the connection, it can with activate the intracellular tyrosine kinase domain area, followed by the activation of signal transduction system, so as to implement the function of regulating the relevant target cells. It has been found that TrkA receptor can regulate the neuronal survival, proliferation, differentiation and apoptosis of the nervous system. At the same time, TrkA also can be expressed in a variety of tumor cells.

\section{The Integration of Nerve Growth Factor}

Nerve growth factor (NGF) is a multifunctional polypeptide substance, it can produce biological effects through the specific target cell surface of nerve growth factor receptor. During the process of forming ovarian cancer, as well as the development and migration process, the amount of the expression of NGF and TrkA can be gradually increased, which can indict that both of them can have a certain relationship with ovarian cancer. TrkA is one of the receptor tyrosine kinase family members, which has typical structure of tyrosine kinase receptor. As a high affinity receptor for NGF and TrkA, after the combination between NGF and TrkA, it can form dimers, which also can activate the intracellular tyrosine kinase domain areas and cause corresponding tyrosine phosphorylation, so as to activate the downstream signal transduction system, regulating the executive function of target cells.

Samples were collected from one cancer hospital from February, 2012 to February, 2013, there were 34 cases of the surgical excision of ovarian cancer (including 30 cases of serous papillary carcinoma and 4 cases of papillary mucinous carcinoma), besides there were 18cases of the junction of the epithelial ovarian tumor (10 cases of the serous and 8cases of the mucinous), there were 30cases of benign epithelial ovarian tumor (21 cases of serous cystadenoma, 9cases of mucinous cystadenoma), the range of age can be from 23-71, the average age is 51 years old. 


\section{The Expression of TrkA Protein in the Benign, Borderline, Malignant Ovarian Epithelial Tumor}

The expression of TrkA protein in malignant ovarian epithelial tumors showed strongly positive expression, while it showed positive expression in borderline epithelial ovarian tumors, there were only? cases that showed weakly positive expression in benign ovarian epithelial tumors, $\mathrm{P}<0.05$ ).

Table 1 The Expression of TrkA Protein in Benign, Borderline, Malignant Epithelial Ovarian Tumor[ (\%)]

\begin{tabular}{|c|c|c|c|c|}
\hline Type & $\begin{array}{c}\text { The total } \\
\text { number of cases }\end{array}$ & Negative & Weakly negative & $\begin{array}{c}\text { Strongly } \\
\text { positive }\end{array}$ \\
\hline Benign & 30 & $26(86.7)$ & $4(13.3)$ & 0 \\
\hline Borderline & 18 & 0 & $8(44.4)$ & $10(55.6)$ \\
\hline Malignant & 34 & 0 & 0 & $34(100.0)$ \\
\hline
\end{tabular}

Table 2 The Expression of TrkA Protein of Serous and Mucinous Tumors in Benign and Borderline Tumors [cases $(\%)$ ]

\begin{tabular}{|c|c|c|c|c|c|}
\hline \multirow{2}{*}{ Type } & \multicolumn{2}{|c|}{ The total number of cases } & Negative & $\begin{array}{c}\text { Weakly } \\
\text { negative }\end{array}$ & $\begin{array}{c}\text { Strongly } \\
\text { positive }\end{array}$ \\
\hline \multirow{2}{*}{$\begin{array}{c}\text { Benign } \\
\text { tumor }\end{array}$} & Serous & 21 & $18(85.7)$ & $3(14.3)$ & 0 \\
\cline { 2 - 6 } & Mucinous & 9 & $8(88.9)$ & $1(11.1)$ & 0 \\
\hline $\begin{array}{c}\text { Borderline } \\
\text { tumor }\end{array}$ & Serous & 10 & 0 & $3(30.0)$ & $7(70.0)$ \\
\cline { 2 - 6 } & Mucinous & 8 & 0 & $5(62.5)$ & $3(37.5)$ \\
\hline
\end{tabular}

Table 3 Relationship between the Expression of TrkA and Clinical Pathology Index

\begin{tabular}{|c|c|}
\hline \multirow{2}{*}{ Clinical pathological index } & $\begin{array}{c}\text { The optimal scale regression method P } \\
\text { value }\end{array}$ \\
\cline { 2 - 2 } & TrkA \\
\hline Gender & 0.901 \\
\hline Age & 0.353 \\
\hline Histological type & 0.228 \\
\hline Tumor location & 0.377 \\
\hline Nerve invasion & 0.134 \\
\hline Lymph node metastasis & 0.011 \\
\hline Tumor size & 0.269 \\
\hline Tumor staging & 0.063 \\
\hline
\end{tabular}

The expression rate of TrkA protein in malignant ovarian epithelial serous and mucinous tumor is the same, which can be expressed in strongly positive expression, while the expression of serous and mucinous tumor in benign and borderline tumor is different. The expression rate of TrkA protein of serous and mucinous tumor in benign epithelial tumor had no significant difference $(\mathrm{P}>$ 0.05), the expression rate of serous and mucus tumor in borderline tumor is statistically significant $(\mathrm{P}<0.05)$. The expressions of TrkA in all tissues of ovarian are all positive, most of them are showed in strongly positive expression, which are mainly in the membrane and cytoplasm of basal layer, infiltration cells at the edge of the coloring. Benign ovarian tumor can show weakly positive expression. The strongly positive expression rate of TrkA in ovarian cancer is significantly higher than that in benign ovarian tumors, therefore, the difference is statistically significant $(\mathrm{P}<0.05)$.

\section{The significance of Expression of Nerve Growth Factor Receptor}

In recent years, the study has confirmed that TrkA can have expression in normal tissue and tumor cells of the multiple non-nervous system, which can be combined mainly by autocrine or paracrine secretion of NGF, so as to perform multiple biological effects. The positive expression of TrkA and its receptor NGF in normal ovarian tissues is very low, but there is high expression in ovarian cancer tissues. From the different rate of the expression of TrkA protein in epithelial ovarian 
tumor, it can be seen that the TrkA expression rate can be increased with the increase of malignancy, which should be positively correlated, which can indicate that the expression of TrkA protein can judge the prognosis of ovarian tumor. This study found that the expression of TrkA protein in serous and mucinous of the benign, borderline epithelial ovarian tumor had different expression, especially in borderline epithelial ovarian tumor. It in some degree can indict the larger differences of different types of tumor, namely, the malignant degree of serous tumors in borderline is higher than that in mucinous tumor. Research results show that the activation of TrkA is very common in the late of advanced malignant serous ovarian tumors. At the same time,the high expression of TrkA in ovarian cancer cells can poorly prompt its prognosis. While it is unknown whether the different classification prognosis of benign epithelial tumors is related to the expression rate of TrkA protein, because of the small number of cases, it can have effect on the statistical results, until the accumulation of enough number of cases are existed in the future, it can provide analysis after long-term follow-up.

This study found that there was close relationship between NGF receptor of TrkA in ovarian tumor with the clinical stage, the higher the degree of malignancy of ovarian cancer is, the more of the NGF receptor of the TrkA expression, which is also more prone to have metastasis with the indicting poor prognosis. This study failed to track the prognosis of the patients, which also failed to accurately assess the effect of TrkA on the prognosis of patients with ovarian cancer, therefore, it needs further study. The relationship between nerve growth factor receptor and tumor has been got more and more attention from people. In fact, cells of cancer may occur translocation, mutation, rearrangement and loss and son on because of the growth factor, the receptor of growth factor and receptor of the mediated intracellular signaling molecule genes, which can make the growth, proliferation and differentiation of cells changed from the controlled state to the uncontrolled state, leading to cancer.

\section{Conclusion}

With the further study on the mechanism of NGF and its receptor in ovarian tumor, in this paper, it shows the expression of TrkA in malignant ovarian tumor tissue is significantly increased than that in benign ovarian tumor tissue, which can indict that the number of TrkA in the tumor cells surface can be regarded as the new method to judge the staging of ovarian cancer, prognosis as well as the aspect of guiding the treatment. Through the gradual understanding of these mechanisms, it can better play the function of the diagnosis and treatment of NGF and its receptor in ovarian tumor.

\section{Reference}

[1] Allen J, Khwaja F, Djakiew D, et al. 2004. Gene therapy of prostate xenograft tumors with a p75NGFR lipoplex. Anticancer Res. vol.24, pp 2997-3003.

[2] Krygier S, Djakiew D. 2001. The neurotrophin receptor p75NGFR is a tumor suppressor in human prostate cancer. Anticancer Res. vol.21, pp3749-3755.

[3] Dolle L, Adriaenssens E, EYBI, et al. 2004. Nerve growth factor receptors and signaling in breast cancer. Curr Cancer Drug Targets. vol.4, pp463-470.

[4] Davidson B, Reich R, Lazarovici P, et al. 2004. Altered expression and activation of the nerve growth factor receptors TrkA and p75 provide the first evidence of tumor progression to effusion in breast carcinoma. Breast Cancer Res Treat. vol.83, pp119-128.

[5] Davidson B, Reich R, Lazarovici P, et al. 2004. Expression of the nerve growth factor receptors TrkA and p75 in malignant mesothelioma. Lung Cancer. vol.44, pp159-165. 